\title{
Terpenoids from Marine Soft Coral of the Genus Lemnalia: Chemistry and Biological Activities
}

\author{
Qihao $\mathrm{Wu}^{1,2}$, Jiadong Sun ${ }^{3}$, Jianwei Chen ${ }^{1}$, Huawei Zhang ${ }^{1}\left(\mathbb{D}\right.$, Yue-Wei Guo ${ }^{1,2, *(\mathbb{D})}$ and \\ Hong Wang ${ }^{1, * \mathbb{D}}$ \\ 1 College of Pharmaceutical Sciences, Zhejiang University of Technology, Hangzhou 310014, China; \\ qihaowu@zjut.edu.cn (Q.W.); cjw983617@zjut.edu.cn (J.C.); hwzhang@zjut.edu.cn (H.Z.) \\ 2 State Key Laboratory of Drug Research, Shanghai Institute of Materia Medica, Chinese Academy of Sciences, \\ 555 Zu Chong Zhi Road, Zhangjiang Hi-Tech Park, Shanghai 201203, China \\ 3 Laboratory of Bioorganic Chemistry, National Institute of Diabetes and Digestive and Kidney \\ Diseases (NIDDK), National Institutes of Health, Bethesda, MD 20878, USA; sunjiadong@gmail.com \\ * Correspondence: ywguo@simm.ac.cn (Y.-W.G.); hongw@zjut.edu.cn (H.W.); Tel.: +86-0571-8832-0622 (H.W.)
}

Received: 2 August 2018; Accepted: 4 September 2018; Published: 9 September 2018

\begin{abstract}
Lemnalia is one of the most widely-distributed marine soft coral in tropical oceans and is known to produce novel terpenoids with a broad spectrum of biological activities. This review provides the first comprehensive overview of terpenoids produced by soft coral Lemnalia since their first discovery in 1974.
\end{abstract}

Keywords: marine soft coral; Lemnalia sp.; secondary metabolites; bioactivity

\section{Introduction}

Marine soft corals continue to be a rich source for the discovery of structurally diverse terpenoids with potential therapeutic applications [1-3]. In recent years, many marine soft corals distributed in the oceans from tropic to polar regions, such as Taiwan and South China Sea, have been chemically investigated and studied for potentially bioactive chemical components [4-6]. Among them, marine soft coral of the genus Lemnalia (Coelenterata, Octocorallia, Alcyonacea) has afforded numerous novel terpenoids with diverse chemical structures, including sesquiterpenes and diterpene glycosides with promising biological activities. Diverse biological properties enabled the Lemnalia-derived marine natural products (MNPs), mainly terpenoids, to attract attention of natural product chemists for the discovery of new drug candidates.

In order to exploit the MNPs of marine soft coral Lemnalia and better understand the medicinal significance of terpenoids from this genus, this review summarizes the chemical and/or biological investigations of soft coral Lemnalia. It covers topics ranging from the distribution of Lemnalia to the isolation, biosynthesis, and biological activities of different types of terpenoids, within a literature survey from 1974 to the present.

\section{Marine Natural Products from Lemnalia sp.}

Soft corals of the genus Lemnalia are distributed all over the oceans. Many of them were chemically investigated, especially those from the South China Sea, Taiwan, and off the coast of Australia and Kenya (Figure 1). Up to 2017, 88 terpenoids (Figures 2 and 3) have been isolated and identified from the marine soft coral of the genus Lemnalia, including L. africana, L. flava, L. philippinensis, L. cervicornis, L. bournei, L. tenuis, L. laevis, L. humesi, L. carnosa, and other unidentified Lemnalia sp. (Table 1). Among all the terpenoids discovered from Lemnalia, 70 of them were found from Lemnalia for the first time, and the other 18 compounds were known from other sources. Sesquiterpenoids are the most 
prominent metabolites from Lemnalia, which can be classified into 14 types, such as nardosinane-type, neolemnane-type, ylangane-type, and other type sesquiterpenoids according to the carbon skeletons of their chemical structures (Scheme 1). Besides, diterpenoids from Lemnalia have a biflorane-based skeleton. As demonstrated in Figure 4, terpenoids were discovered and characterized by different ratio of structural types. Nardosinane-type sesquiterpenoids (40\%) were commonly considered as chemotaxonomic markers of soft corals of genus Lemnalia (Table 1 and Figure 4); Cadinane-type sesquiterpenoids (14\%) were mainly discovered from one soft coral sample collected off Broadhurst Reef, Townsville, Australia; Biflorane-type diterpenoids (13\%) were mainly obtained from South China Sea; Ylangane-type sesquiterpenoids (10\%) were mainly derived from Formosan soft corals.

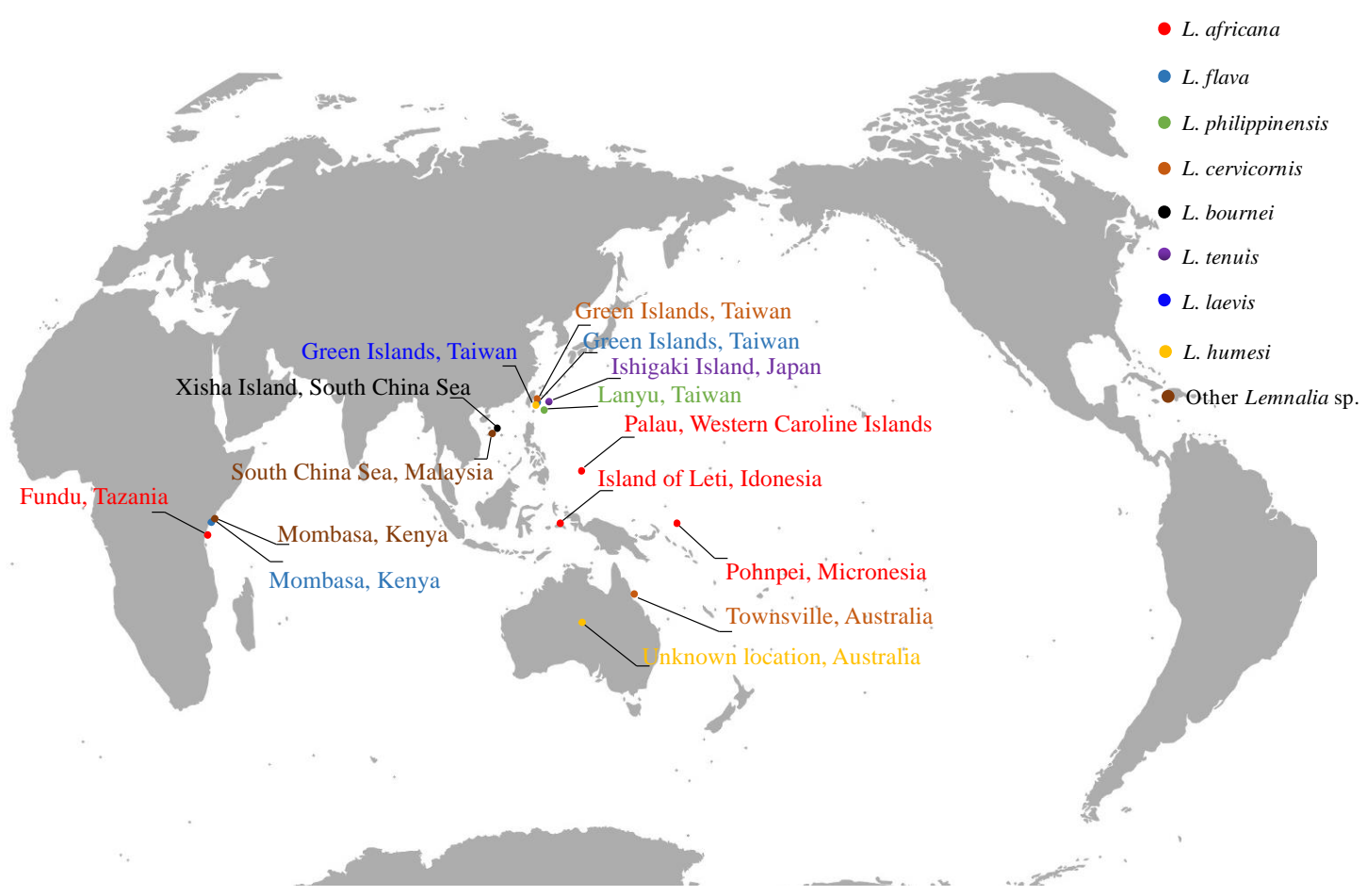

Figure 1. Global distribution of the chemically investigated Lemnalia marine soft coral according to their species. 


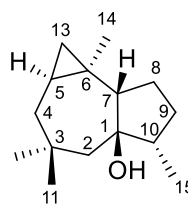

1

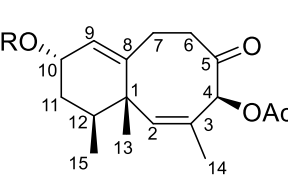

6, $\mathrm{R}=\mathrm{H}$

7, $R=A c$

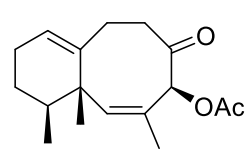

12

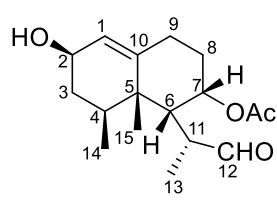

2

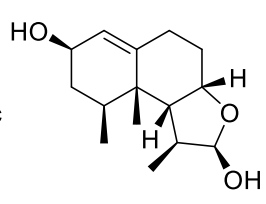

3
$\mathrm{HO}$,

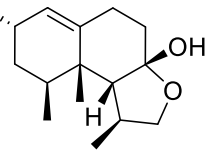

(1)<smiles>C[C@@H]1CC(=O)CC2CC[C@]3(O)OC[C@H](C)[C@@]3(C)[C@]21C</smiles>

11

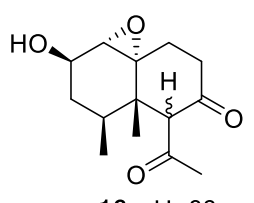

16, $H=6 \beta$

17, $H=6 \alpha$<smiles>C/C=C1/CCC(C)=CC2C=C(C)CCC12</smiles>

18

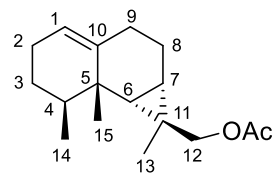

13

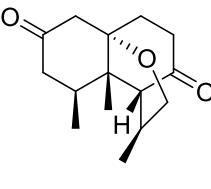

14

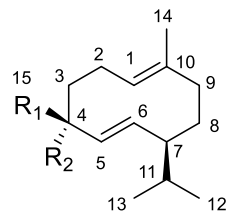

19, $\mathrm{R}_{1}, \mathrm{R}_{2}=\mathrm{CH}_{2}$

20, $\mathrm{R}_{1}=\mathrm{Me}, \mathrm{R}_{2}=\mathrm{OH}$<smiles>[R2]C1([R2])C=C[C@@H](C(C)C)CCC(=C)[C@H]2O[C@@H]21</smiles>

21, $\mathrm{R}_{1}, \mathrm{R}_{2}=\mathrm{CH}_{2}$ 23, $\mathrm{R}_{1}=\mathrm{Me}, \mathrm{R}_{2}=\mathrm{OH}$

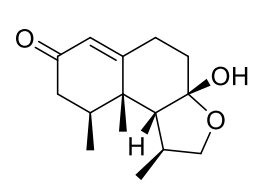

22<smiles>[R]C1C[C@H](O)C2=CCC[C@@H](C)[C@@]2(C)[C@H]1C(C)=O</smiles>

24, $\mathrm{R}=\mathrm{Ac}$

25, $\mathrm{R}=\mathrm{OH}, 1(10)$ epoxy 26, $R=A c, 1(10)$ epoxy

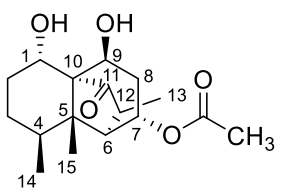

27

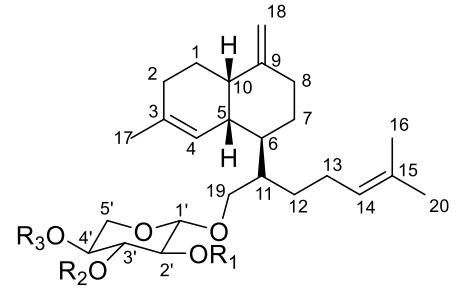

28, $R_{1}=R_{2}=R_{3}=H$ 29, $R_{1}=A c ; R_{2}=R_{3}=H$ 30, $\mathrm{R}_{2}=A c ; \mathrm{R}_{1}=\mathrm{R}_{3}=\mathrm{H}$ 31, $R_{3}=A c ; R_{1}=R_{2}=H$

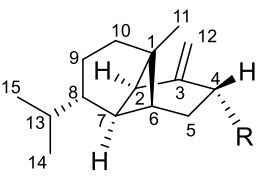

32, $\mathrm{R}=\mathrm{OCHO}$ 33, $\mathrm{R}=\mathrm{OH}$

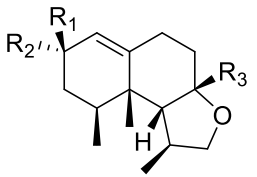

37, $\mathrm{R}_{1}=\mathrm{H}, \mathrm{R}_{2}=\mathrm{OM}$

38, $\mathrm{R}_{1}=\mathrm{OMe}, \mathrm{R}_{2}=\mathrm{H}$

39, $\mathrm{R}_{1}=\mathrm{R}_{2}=\mathrm{O}, \mathrm{R}_{3}=\mathrm{OMe}$

40, $\mathrm{R}_{1}=\mathrm{OH}, \mathrm{R}_{2}=\mathrm{H}, \mathrm{R}_{3}=\mathrm{OH}$

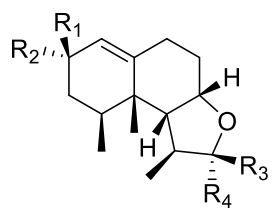

41, $\mathrm{R}_{1}=\mathrm{R}_{2}=\mathrm{O}, \mathrm{R}_{3}=\mathrm{H}, \mathrm{R}_{4}=\mathrm{OMe}$

42, $\mathrm{R}_{1}=\mathrm{H}, \mathrm{R}_{2}=\mathrm{OAc}, \mathrm{R}_{3}=\mathrm{OMe}, \mathrm{R}_{4}=\mathrm{H}$

45, $\mathrm{R}_{1}, \mathrm{R}_{2}=\mathrm{O}, \mathrm{R}_{3}=\mathrm{OMe}, \mathrm{R}_{4}=\mathrm{H}$

46, $\mathrm{R}_{1}=\mathrm{OH}, \mathrm{R}_{2}=\mathrm{H}, \mathrm{R}_{3}, \mathrm{R}_{4}=\mathrm{O}$<smiles>[R3][C@@H]1C[C@H](O)[C@H](C(C)=O)[C@]2(C)C1=CC([R2])([R2])C[C@@H]2C</smiles>

43, $\mathrm{R}_{1}=\mathrm{R}_{2}=\mathrm{O}, \mathrm{R}_{3}=\mathrm{H}$

44, $\mathrm{R}_{1}=\mathrm{R}_{2}=\mathrm{O}, \mathrm{R}_{3}=\mathrm{OH}$

47, $\mathrm{R}_{1}=\mathrm{OH}, \mathrm{R}_{2}=\mathrm{H}, \mathrm{R}_{3}=\mathrm{H}$

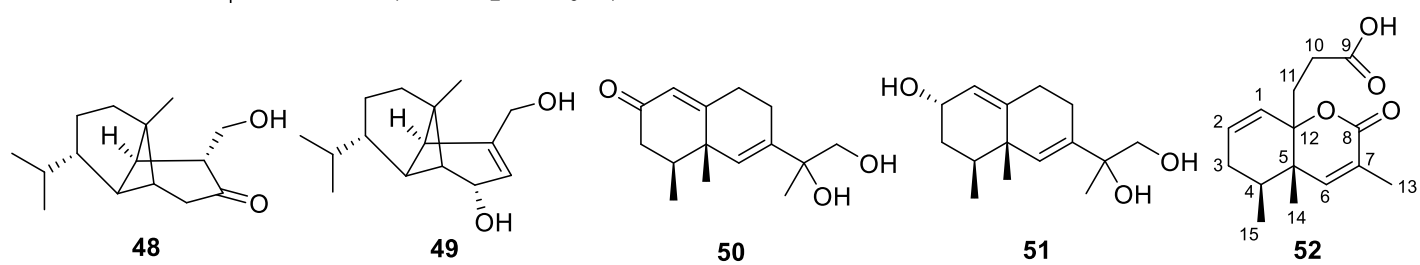

Figure 2. Chemical structures of compounds 1-52. 
<smiles>Cc1cc2c(cc1O)[C@H](C(C)C)C(=O)C[C@H]2C(C)C</smiles>

53<smiles>CC(=O)Oc1cc2c(cc1C)[C@@H](C(C)C)C(=O)C[C@@H]2C</smiles>

54<smiles>COc1cc2c(cc1C)[C@@H](C(C)C)C(=O)C[C@H]2C</smiles>

55<smiles>Cc1cc2c(cc1O)[C@@H](C)C[C@@H](O)[C@H]2C(C)C</smiles>

56<smiles>COc1cc2c(cc1C)C(C(C)C)=CC[C@H]2C</smiles>

57<smiles>COc1cc2c(cc1C)[C@@](O)(C(C)C)CC[C@H]2C</smiles>

58, $4 S$

$59,4 R$

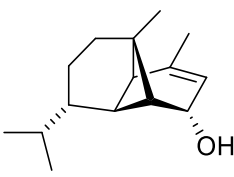

66<smiles>Cc1cc2c(cc1O)[C@@H](C)C[C@@H](O)[C@]2(O)C(C)C</smiles>

$60,4 R$

$61,4 S$

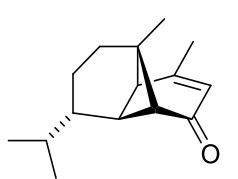

67<smiles>COc1cc2c(cc1C)[C@H](C(C)C)[C@H](O)C[C@H]2C</smiles>

62<smiles>[R]CC(C)C1=C2C=C(C(=O)OC3C[C@H](C)c4cc(OC)c(C)cc4[C@@H]3C(C)C)CC[C@H]2[C@H](C)CC1</smiles>

63
$64, \mathrm{R}=\mathrm{OH}$

65, $\mathrm{R}=\mathrm{OAC}$

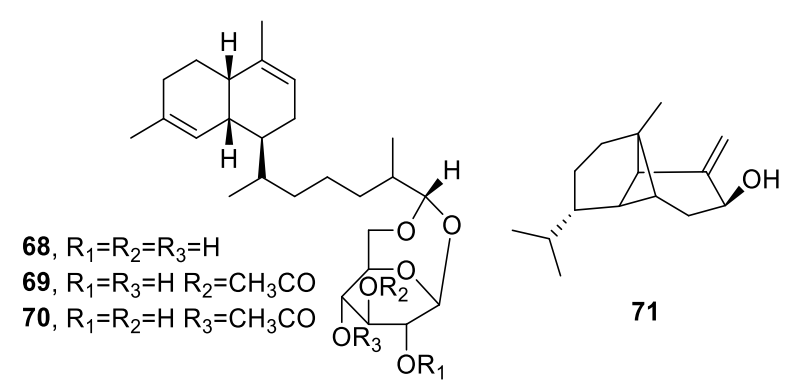

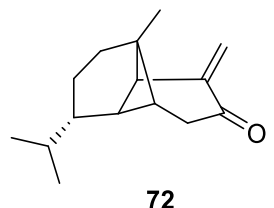<smiles>[R]C1([R2])C=C2CCC([R])([R])C(C(C)=O)C2(C)C(C)C1</smiles>
73, $\mathrm{R}_{1}=\mathrm{H}, \mathrm{R}_{2}=\mathrm{OH}, \mathrm{R}_{3}=\mathrm{H}, \mathrm{R}_{4}=\mathrm{OCHO}$ 74, $\mathrm{R}_{1}=\mathrm{H}, \mathrm{R}_{2}=\mathrm{OH}, \mathrm{R}_{3}=\mathrm{OH}, \mathrm{R}_{4}=\mathrm{H}$ 75, $\mathrm{R}_{1}=\mathrm{OH}, \mathrm{R}_{2}=\mathrm{H}, \mathrm{R}_{3}=\mathrm{H}, \mathrm{R}_{4}=\mathrm{OH}$ 76, $\mathrm{R}_{1}=\mathrm{H}, \mathrm{R}_{2}=\mathrm{OH}, \mathrm{R}_{3}, \mathrm{R}_{4}=\mathrm{O}$

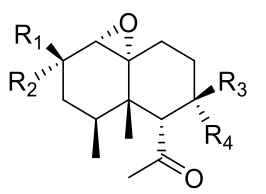

77, $\mathrm{R}_{1}=\mathrm{H}, \mathrm{R}_{2}=\mathrm{OH}, \mathrm{R}_{3}=\mathrm{OH}, \mathrm{R}_{4}=\mathrm{H}$ 78, $\mathrm{R}_{1}=\mathrm{OH}, \mathrm{R}_{2}=\mathrm{H}, \mathrm{R}_{3}=\mathrm{OH}, \mathrm{R}_{4}=\mathrm{H}$ 79, $\mathrm{R}_{1}=\mathrm{H}, \mathrm{R}_{2}=\mathrm{H}, \mathrm{R}_{3}=\mathrm{OH}, \mathrm{R}_{4}=\mathrm{H}$<smiles>CC(=O)OC1C(=O)CCC2=CC(=O)CC(C)[C@]2(C)/C=C\1C</smiles>

80<smiles>CC1COC2=C1C1(C)C(=CCC2)CCC1C</smiles>

88<smiles>CC(=O)OCCC(O)C(O)COC(O)C(O)COC(C)=O</smiles>

84<smiles></smiles>

82<smiles>C[C@H]1[C@@H](O)CCC2=CC[C@H](F)[C@H](C)[C@]21C</smiles>

83<smiles>C=C(C)COO</smiles>

86

87

Figure 3. Chemical structures of compounds 53-88. 

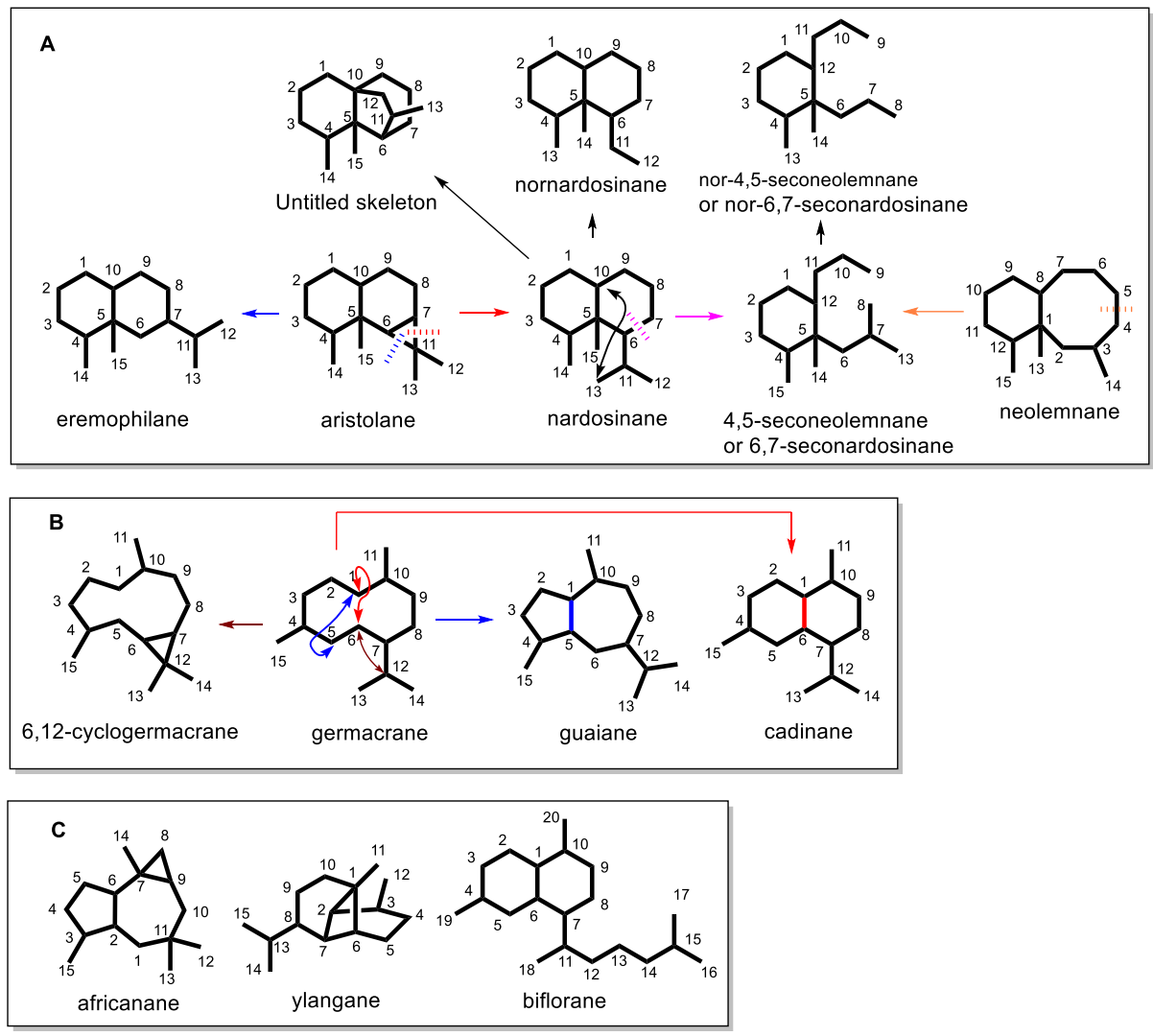

Scheme 1. Various carbon skeletons of metabolites from soft coral of the genus Lemnalia. (A) Aristolane related carbon skeletons from soft coral Lemnalia; (B) Germacrane related carbon skeletons from soft coral Lemnalia; (C) Other carbon skeletons from soft coral Lemnalia.
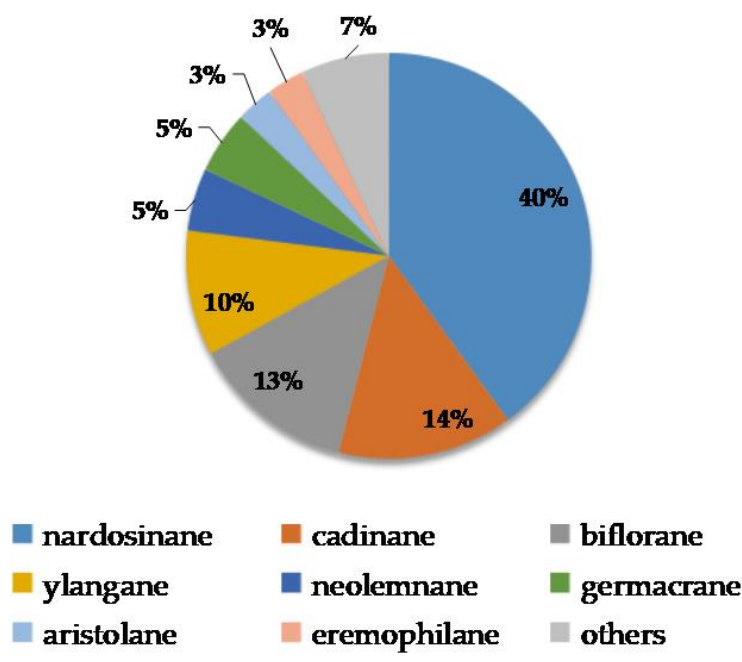

Figure 4. Terpenoids discovered from Lemnalia with different ratio of structural types.

\subsection{Lemnalia africana}

To the best of our knowledge, the first chemical investigation of Lemnalia (L. africana; collected around the island of Leti, province of Maluku, Indonesia) was conducted by Losman's lab in 1974 [7]. Two years later, Karlsson reported the absolute configuration (AC) of the new type of tricyclic sesquiterpene, africanol (1) by single-crystal X-ray diffraction (XRD) analysis [8], determined to be $1 R, 5 S, 6 R, 7 S, 10 S$ which was the enantiomer of the previously assigned structure. The biogenetic pathway of $\mathbf{1}$ was also proposed, as shown in Figure 5. 


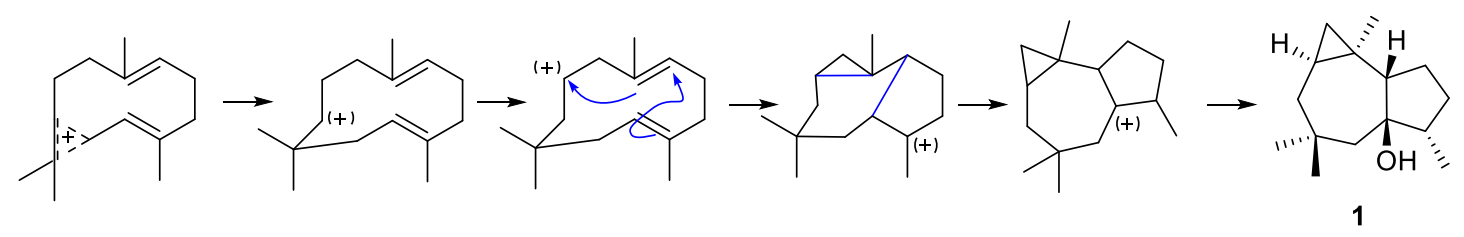

Figure 5. Plausible biogenetic pathway of compound $\mathbf{1 .}$

Although the first metabolite from Lemnalia was reported as a tricyclic sesquiterpenes (africanol), the most typical metabolites were sesquiterpenes with nardosinane skeleton (Scheme 1). In a study of Australian soft coral reported in 1980, Bowden and co-workers described the isolation and structural elucidation of two new nardosinane-type sesquiterpenes ( 2 and 3 ), along with a novel norsesquiterpene (5) from L. africana [9]. Besides, this study also highlighted that the skeleton of nardosinane-type sesquiterpenoids were of specific stereochemistry at $C-4$ and $C-5$ positions with $\beta$-orientation. In fact, this hypothesis was further evidenced by natural product studies of many other marine soft corals, such as Paralemnalia thyrsoides and Nephthea chabroli [10-12]. The two different collections of L. africana, namely G12607 and G12604, were collected in deep water by scuba or snorkeling over shallow reefs. The chemical structures and ACs of these compounds were further confirmed by XRD or/and chemical transformations. The second specimen of L. africana (G12604) afforded a predominant product named $(2 R, 11 S, 12 R)$-lemnal-1(10)-ene-2,12-diol (3). In fact, the AC of hydroxyl groups at C-2 of 2 and 3 were assigned as $2 \beta$ by the comparison of ${ }^{1} \mathrm{H}$ NMR spectra between two isolates and a known compound from L. carnosa with a $2 \alpha$-hydroxy group named lemnacarnol (4) [13], which was structurally characterized by XRD analysis. Finally, the most unexpected metabolite was a nornardosinane-type sesquiterpenoid named (2R, 7S)-7-formyloxy-2-hydroxy-12-nornardosin-1(10)-en-11-one (5) [9].

One year later in 1981, Izac and co-workers reported the discovery of two new sesquiterpenoids (6 and 7) with unprecedented ring systems and an eremophilane-derived sesquiterpene diol (8) from pacific-derived soft coral L. africana [14]. The animals were collected in Palau, Western Caroline Islands and a $\mathrm{CHCl}_{3} / \mathrm{MeOH}$ extract was chemically investigated. This research indicated the extension of the biosynthetic ability of soft coral Lemnalia by representing an additional skeleton (neolemnane-type) aside from the classic nardosinane-type sesquiterpenoid and africanol derivatives. The ring-enlarged neolemnane-type sesquiterpenoid also showed spectroscopic features similar to the nardosinane-type sesquiterpenoids with three methyl groups, and one tri-substituted carbon-carbon double bond. Based upon the biogenetic relationship of compounds with the nardosinane (as known as lemnalane) [15] sesquiterpenoids which are major components of Lemnalia species, it was suggested that the numbering sequence of ring-enlarged 6/8 ring system be changed, as shown in Scheme 1. Also, since the biogenetic relationship of the two different sesquiterpenoid types (nardosinane (lemnalane) and the new skeleton) are closely related, the new skeleton was named as neolemnane. The structural identification of compound 6 $((1 \beta, 2 Z, 4 \beta, 10 \alpha, 12 \beta)-4$-acetoxy-10-hydroxy-neolemna-2,8-dien-5-one) was straightforward. Since it was obtained as a crystal and consequent XRD analysis allowed not only to unambiguous recognize its structure, but also to define its relative configuration as $1 S^{*}, 4 S^{*}, 10 S^{*}, 12 S^{*}$. From the less polar fraction, the diacetate $7((1 \beta, 2 Z, 4 \beta, 10 \alpha, 12 \beta)-4,10$-diacetoxy-neolemna-2,8-dien-5-one) was also determined by NMR analysis. At last, the chemical structure of sesquiterpene diol was characterized as eremophila-6,10-diene-11,12-diol (8).

In 1992, a new halogenated norsesquiterpenoid, napalilactone (9), was isolated from the soft coral L. africana collected in Pohnpei, Federated States of Micronesia [16]. Despite the fact that the chlorine-containing metabolites are ubiquitous in marine-derived invertebrates, no chlorinated sesquiterpenoid or norsesquiterpenoid was reported from soft coral until napalilactone was reported. Along with the novel metabolite 9, two known compounds (10-11) $[17,18]$ with higher polarity were also isolated and identified. Biogenetically, the biosynthetic pathway of 9, involving the intermediate (9b), a known norsesquiterpenoid that was generated from 1(10)-aristolene (9a) [15], is shown in Figure 6. The generation of $\mathbf{9}$ involved the hydrolysis of the $\beta$-diketone of $\mathbf{9 b}$ followed by a 
haloperoxidase-generated chloronium ion-assisted lactonization. Several years later in 2002, Vyvyan and co-workers synthesized the spirolactone core of $\mathbf{9}$ in five steps from 2-methyl-2-cyclohexen-1-one or 2,3-dimethyl-2-cyclohexen-1-one [19].

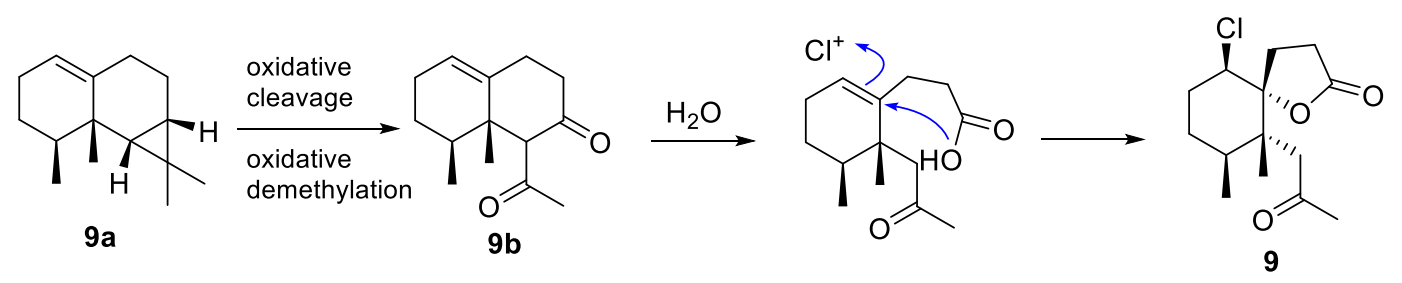

Figure 6. Plausible biogenetic pathway of 9.

In fact, the first biological investigation of terpenoids from L. africana was reported in 1993 by Scheuer's lab [20]. In this study, the biological activity of an EtOAc extract of L. africana (collected from Pohnpei, Mincronesia) was tested. The extract with anti-leukemia activity in the P-388 assay afforded a total of sixteen sesquiterpenoids and norsesquiterpenoids, including six new compounds (12-17). These new compounds were identified as 4 -acetoxy-2,8neolemnadien-5-one (12), 12-acetoxy-1(10)-aristolene (13), 2,7-nardosinoxanedione (14), 4-acetoxy-6,10-

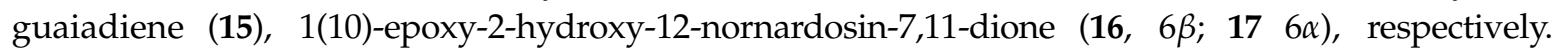
The known compounds were readily identified as bicyclogermacrene (18) [18], germacrene D (19) [21], 1,6-germacradien-5-ol (20) [22], 1(11),5(12),6-germacratrien-2-ol acetate (21) [23], (1 $\beta, 2 Z, 4 \beta, 10 \alpha, 12 \beta)$ -4-acetoxy-10-hydroxy-neolemna-2,8-dien-5-one (6) [14], lemnacarnol (4) [13], 2-oxolemnacarnol (22) [18,24], eremophila-6,10-diene-11,12-diol (8) [14], $(1 \beta, 2 Z, 4 \beta, 10 \alpha, 12 \beta)-4,10$-diacetoxy-neolemna-2,8 -dien-5-one (7) [14], and 2-acetoxy-1(11),6-germacradien-5-ol (23) [22]. The main active compound in the extract was then found to be the known compound $\mathbf{8}$. Compound $\mathbf{8}$ displayed cytotoxic activity against leukemia in the P-388 assay at $1 \mu \mathrm{g} / \mathrm{mL}$ whereas it had cytotoxicity in the CV-1 assay at $10 \mu \mathrm{g} / \mathrm{mL}$. It is worth mentioning that the authors accomplished the isolation of terpenoids resulting in seven different skeletons, which further supported the chemical diversity and complexity of the secondary metabolites from marine soft coral L. africana.

The most recent chemical investigation of L. africana was in 2008 by Kashman's lab. They reported the chemical structures of three new nornardosinanes named nardosinanols G-I (24-26), and one new tricyclic sesquiterpenoid named lemnafricanol (27) from a $\mathrm{CH}_{2} \mathrm{Cl}_{2}$ extract of $L$. africana [25]. It was described that the soft coral was collected at Fundu (deep gap south), Pemba Island, Tanzania. It was also noted that compounds $\mathbf{2 4}$ and $\mathbf{2 7}$ were found to be toxic to brine shrimp with $\mathrm{LC}_{50}$ values of 0.35 and $0.32 \mu \mathrm{M}$, respectively.

\subsection{Lemnalia flava}

During the studies of chemical composition in the soft coral L. flava collected on Shelly Reef, off Mombasa, Kenya, Kashman's lab discovered four new diterpene glycosides (28-31) [26]. This research was the first chemical investigation of L. flava. During the investigation, the major composition of an EtOAc extract was determined to be lemnaflavoside (28). Unlike the abundance of lemnaflavoside from the sample, the other three metabolites were minor analogs with one hydroxyl group acetylated at various positions in the D-xylose moiety of 28.

It was reported that a new ylangene-type sesquiterpenoid (32) was isolated from the Formosan soft coral L. flava [27] along with two related known ones, lemnalol (33) [28] and cervicol (34) [29]. It is worth mentioning that the parent hydrocarbon of ylangane is a stereoisomer of $\alpha$-copaane as regards the orientation of the isopropyl group at C-8 ( $\alpha$-orientation for ylangane, $\beta$-orientation for copaane) [30]. The animals were collected at the Green Island located in the southeast coast of Taiwan by scuba. The resulting new metabolite (32) was identified as $(1 S, 2 S, 4 R, 6 S, 7 R, 8 S)-4 \alpha$-formyloxy- $\beta$-ylangene by NMR analysis and chemical transformation. Biologically, the authors evaluated the in vitro anti-inflammatory activity of these metabolites. The new compound $\mathbf{3 2}$ was found to be able to 
significantly inhibit iNOS (inducible nitric oxide synthetase) protein expression and 34 was shown to be active in inhibiting both iNOS and COX-2 (cyclooxygenase-2) proteins expression.

Another discovery of sesquiterpenoid from Formosan soft coral L. flava was reported by Sheu's lab in 2011. Still, the animals were collected by hand using scuba off the coast of Green Island, Taiwan. Four new nardosinane-type sesquiterpenoids, flavalins A-D (35-38) were isolated [31]. The structures were elucidated by extensive spectroscopic analyses. Flavalin B (36) was further determined by XRD analysis. The oxidative patterns of these polyoxygenated nardosinane-type sesquiterpenoids, especially compound 35, which featured a unique tetracyclic oxacage ring, was different from those secondary metabolites discovered from soft coral of the genus Lemnalia before. From biogenetical standpoint, the more complex products could be generated from normal nardosinane-type sesquiterpenoid, such as nardosinanol C (Figure 7) [25], a proposed precursor of these compounds, by allylic rearrangement and cyclization. These metabolites were shown to possess different biological activities, for instance, flavalin A (35) was found to exhibit inhibition of lipopolysaccharide (LPS)-induced iNOS and COX-2 protein expression in a dose-dependent manner with $\mathrm{ED}_{50}$ values of $4.8 \pm 0.3 \mu \mathrm{g} / \mathrm{mL}$ and $6.2 \pm 0.6 \mu \mathrm{g} / \mathrm{mL}$, respectively. Besides, both flavalins A and B (35 and 36) showed significant neuroprotective activity. Pretreatment of $\mathbf{3 5}$ and $\mathbf{3 6}$ at different concentrations on SH-SY5Y cells significantly reduced 6-hydroxydopamine (6-OHDA) induced cytotoxicity at a concentration of $20 \mu \mathrm{M}$.

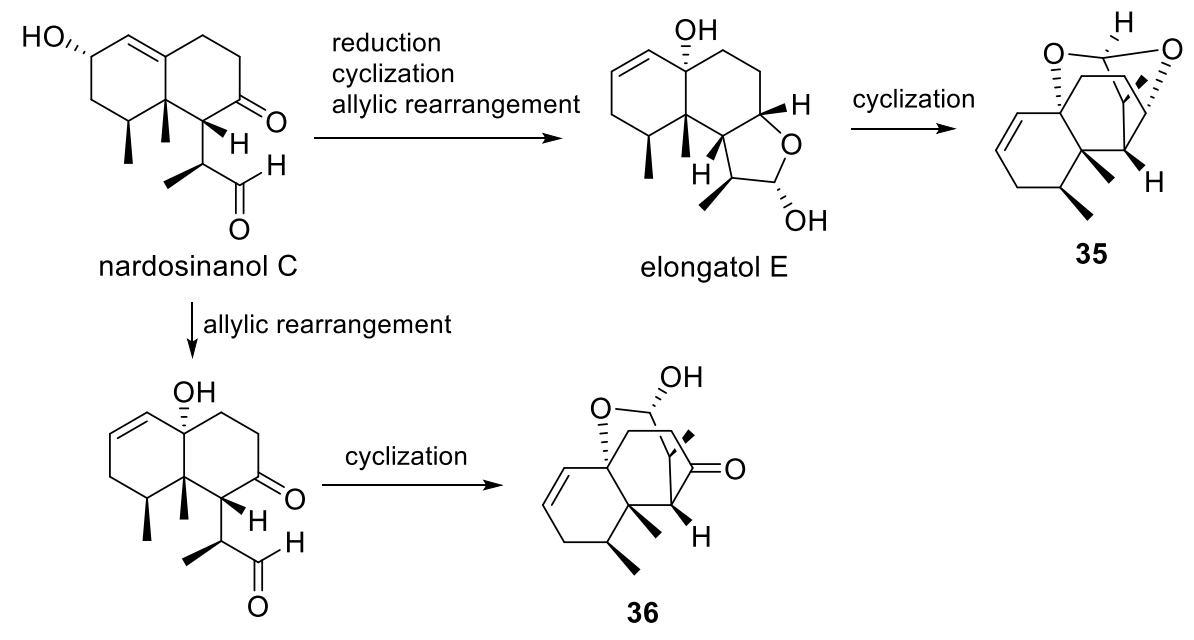

Figure 7. Plausible biogenetic pathway of $\mathbf{3 5}$ and $\mathbf{3 6 .}$

In the same year, Sheu's lab also reported the continuing study of the sample collected at Green Island. A total of four new nardosinanes named flavalins E-H (39-42) [32] and two new nornardosinanes named flavalins I (43) and J (44), along with five known compounds, 2-oxolemnacarnol (22), lemnacarnol (4), armatin F (45) [29], (2R)-2-hydroxylemnal-1(10)-en-12-one (46) [24], and laevinol B (47) [33] were obtained. For the first time, the AC of compound 46 was assigned as $R$ configuration at C-2 by Mosher's method. The presence of both the C-12 methoxy epimers $(41,45)$ and the use of $\mathrm{MeOH}$ during the purification suggest that methoxy-containing compounds 39, 41, 42, and 45 might be artifacts. A further experiment was conducted to address this issue. It was reported that the methoxy group in flavalin E (39) was not obtained from 2-oxolemnacarnol (22) with the presence of $\mathrm{MeOH}$ in silica gel for ten days. Thus, it was believed that the methoxy containing compounds were genuine natural products and the methoxy group was obtained during the generation of secondary metabolites in natural environment. All of the molecules were evaluated for cytotoxicity against a panel of cancer cell lines, including human breast carcinoma (MCF-7), human colon carcinoma (WiDr), human laryngeal carcinoma (HEp 2), human medulloblastoma (Daoy), T-cell acute lymphoblastic leukemia (CCRF-CEM), colon adenocarcinoma (DLD-1), human promyelocytic leukemia (HL-60), and murine leukemia (P388D1) but none displayed cytotoxicity at $20 \mathrm{\mu g} / \mathrm{mL}$. 


\subsection{Lemnalia philippinensis}

Two oxygenated ylangene sesquiterpenoids, philippinlins A (48) and B (49) [34], and one known compound, lemnalol (33) [28], were obtained from the soft coral L. philippinensis. The animals were collected from the coast of Lanyu, Taiwan. It was noted that the ACs of two new products were tentatively assigned as same as lemnalol (33), based mainly on the NMR analysis and biogenetic consideration. As part of their biological experiment, the cytotoxicity of philippinlins and lemnalol against human liver carcinoma (HepG2), human breast carcinoma (MDA-MB231) and human lung adenocarcinoma epithelial cells (A549) were evaluated. Philippinlin A was shown to be cytotoxic against HepG2, MDA-MB231, and A549 cancer cell lines with $\mathrm{IC}_{50}$ values of 16.0, 16.3, and $15.8 \mu \mathrm{g} / \mathrm{mL}$, respectively.

The continuing chemical investigation of the Formosan soft coral L. philippinensis, with the same collection mentioned above, gave three new sesquiterpenoids, including two new eremophilane-type metabolites, philippinlins C (50) and D (51), and a new 4,5-seconeolemnane, philippinlin E (52) [35]. Besides, one known eremophilane-type compound, eremophila-6,10-diene11,12-diol (8), and one known neolemnane-type compound, $(1 \beta, 2 Z, 4 \beta, 10 \alpha, 12 \beta)$-4-acetoxy-10-hydroxyneolemna-2,8-dien-5-one (6), were also identified from the same extract. Although the NMR spectroscopic analyses of the two new eremophilane-type compounds were able to establish the gross structures, the relative configuration of the chiral center at C-11 remained unknown. In this paper, the authors also focus on the plausible biosynthetic pathway of philippinlin E (52). In fact, it was proposed that $\mathbf{5 2}$ was generated from the oxidation with ring cleavage of a neolemnane, followed by the subsequent nucleophilic conjugate substitution (Figure 8). As a routine screening of biological activity, all the compounds were tested against HepG2, MDA-MB231, and A549 carcinoma cells yet none of them were cytotoxic.

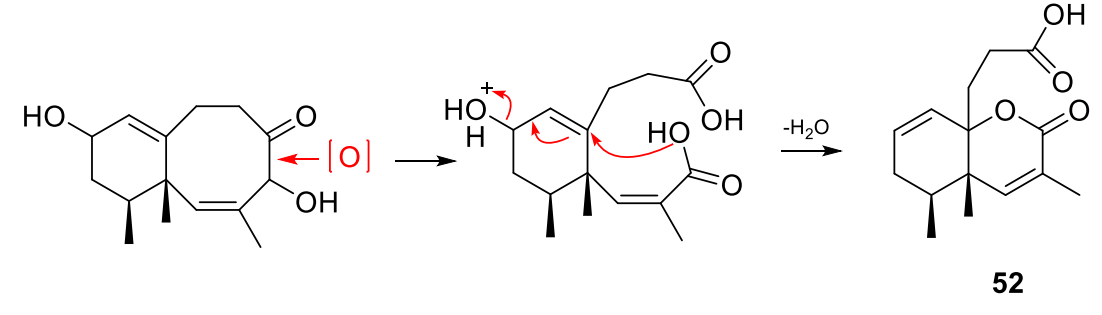

Figure 8. Plausible biogenetic pathway of 52.

\subsection{Lemnalia cervicornis}

The search for natural products from Australian soft coral L. cervicornis afforded thirteen novel sesquiterpenoids whose structures were based on the cadinane. The soft corals were collected at Broadhurst Reef, $60 \mathrm{~km}$ E.N.E. of Townsville. Eleven aromatic metabolites (53-63) and two minor metabolites with more saturated structures (64-65) were isolated [36]. They were identified as $(1 S, 4 R)$ 7-hydroxycalamenen-3-one (53), (1S,4R)-7-acetoxycalamenen-3-one (54), (1S,4R)-7-methoxycalamenen3-one (55), (1S,3R,4S)-calamenen-3,7-diol (56), (1S)-7-methoxy-1,2-dihydrocadalene (57), (1S,4S)7-methoxycalamenen-4-ol (58), (1S,4R)-7-methoxycalamenen-4-ol (59), (1S,3R,4R)-calamenen-3,4,7-triol (60), (1S,3R,4S)-calamenen-3,4,7-triol (61), (1S,3R,4R)-methoxycalamenen-3-ol (62), (1S,3R,4R)-7methoxycalamenen-3-yl acetate (63), 12-hydroxyzonarene (64), and 12-acetoxyzonarene (65). The chemical transformations of these compounds were also carried out.

Four ylangene-type sesquiterpenoids, including two new compounds cervicol (34) and isolemnalol (66) [29], two known lemnalol (33) [28] and 4-oxo- $\alpha$-ylangene (67) [37] were isolated from Formosan soft coral L. cervicornis. Animals were collected at Green Island, off Taiwan. The in vitro cytotoxicity against selected cancer cells was measured. Only the known compound lemnalol exhibited cytotoxicity against P-388 and HT-29 with $\mathrm{ED}_{50}$ values of $16.3 \mu \mathrm{M}$ and $10.5 \mu \mathrm{M}$, respectively. In 2008, Wen and co-workers tested the anti-inflammatory and analgesic effects of a 
natural marine compound lemnalol (33) [28] isolated from Formosan soft coral L. cervicornis [38]. The anti-inflammatory and anti-nociceptive properties were investigated in LPS-stimulated RAW 264.7 cells and carrageenan-injected rats. The results indicated the lemnalol could be a potent therapeutic agent for inflammatory pain.

\subsection{Lemnalia bournei}

Lemnabourside (68), a novel diterpene glycoside with D-glucose attached to a diterpene aldehyde through an acetal linkage, was isolated from the soft coral of L. bournei [39]. The fresh Chinese soft corals were collected from South China Sea near the Xisha Islands. The stereochemistry of $\mathbf{6 8}$ was solved by careful interpretation of the well-resolved NOESY correlations and its ${ }^{1} \mathrm{H}-{ }^{1} \mathrm{H}$ coupling constants. Finally, only the ACs at C-15 and C-16 could be determined as 15R, 16S, while the other chiral centers at C-5, C-6, C-10, C-11 remained unknown. Four years later in 1998, the Zhang lab further reported two new diterpene glycosides, lemnaboursides B (69) and C (70), from South China Sea soft coral L. bournei [40]. In this article, the animals were collected from the same location as a previous collection aforementioned. Structurally, the NMR spectroscopic data of these two compounds showed high similarity with the known compound 68. Detailed analysis of these data revealed the two new compounds were analogs of 68 with monoacetylation of the sugar residue at different hydroxyl groups. Biologically, three metabolites only showed weak cytotoxicity against HepA (hepatoma ascites), $\mathrm{S}_{180} \mathrm{~A}$ (sarcoma 180 ascites), and EAC (Ehrlich ascites carcinoma) cells with $\mathrm{IC}_{50}$ values ranging from 27.4 to $186.9 \mu \mathrm{g} / \mathrm{mL}$.

\subsection{Lemnalia tenuis}

The first discovery and structure elucidation of the well-known metabolite lemnalol (33) was from the soft coral L. tenuis Verseveldt, reported by Kikuchi and co-workers [28]. The animals were collected from the coral reefs of Ishigaki Island (Okinawa, Japan) and then extracted by EtOAc. The chemical structure of 33 was solved by a combination of NMR analysis, chemical transformation, and XRD analysis. A year later in 1983, Kikuchi and co-workers tested the cytotoxic activities of lemnalol and its derivatives [41]. The new compound lemnalol could activate peritoneal exudate cells (PEC), exhibiting cytotoxic effects in vitro. Surprisingly, compound 71, the C-4 epimer of lemnalol showed no PEC-mediated or direct cytotoxicity while the derivative with an $\alpha, \beta$-unsaturated ketone (72) showed direct cytotoxicity in vitro. Based on the biological results, it was reasonable to speculate that the $4 \alpha$-configuration is quite essential for in vitro cytotoxic activity by PEC-mediated cytotoxicity.

\subsection{Lemnalia laevis}

The only chemical study of soft coral L. laevis was reported in 2005 by Duh and co-workers. They investigated the chemical composition of the animals collected at Green Island, off Taiwan, which resulted eight new nornardosinane sesquiterpenoids, laevinols A (73), B (47), $\mathrm{C}-\mathrm{H}$ (74-79), a new neolemnane sesquiterpenoid, laevinone A (80) [33], along with two known compounds, eremophila-6,10-diene-11,12-diol (8) [14] and $6 \beta$-acetyl- $4 \beta, 5 \beta$-dimethyl-1(10) $\alpha$ epoxy-2 $\beta$-hydroxy-7-oxodecalin (81) [20]. Among all the metabolites, only the known compound 8 exhibited in vitro cytotoxicity against P-388 (mouse lymphocytic leukemia) cells and HT-29 (human colon adenocarcinoma) cells with $\mathrm{ED}_{50}$ values of 0.21 and $0.33 \mu \mathrm{g} / \mathrm{mL}$, respectively.

\subsection{Lemnalia humesi}

The Australian soft corals $L$. humesi gave two new aristolane-type sesquiterpenoids, $(4 R, 5 S, 6 R, 7 S)$-aristol-9-en-3-one (82) and (3S,4R,5S,6R,7S)-aristol-9-en-3-ol (83) [42]. The new metabolites were identified by NMR spectroscopic data and further confirmed by chemical conversion. Besides, the AC of the hydroxyl group at C-3 in $\mathbf{8 3}$ was determined as $3 S$. 


\subsection{Other Lemnalia sp.}

Lemnalosides A-D (84-87), four bisabolane-type bicyclic diterpene glycosides and one known diterpene lemnabourside (69), were isolated from marine soft coral Lemnalia collected from South China Sea, Malaysia [43]. The $\mathrm{CH}_{2} \mathrm{Cl}_{2}-\mathrm{MeOH}$ extract exhibited activity in hyphae formation inhibition (HFI) assay against Streptomyces 85E with a concentration of $20 \mu \mathrm{g} /$ disk. Due to the limited material obtained from the purification, only 84-86 and $\mathbf{6 9}$ were evaluated for HFI activity. Lemnaloside B (85) showed the best activity with an inhibitory clear zone with $18 \mathrm{~mm}$ at a concentration of $20 \mu \mathrm{g} / \mathrm{disk}$. Besides, the clear inhibitory zone was still visible at the concentration of $2.5 \mu \mathrm{g} /$ disk. Lemnaloside A (84) only showed moderate activity $(11 \mathrm{~mm}$ ) with a concentration of $2.5 \mu \mathrm{g} /$ disk while no activity was observed for compounds 86 and $\mathbf{6 9}$ at the same concentration. Extraction of Lemnalia sp. and isolation of a new nardosinane-type sesquiterpenoid, nardosinanol A (88), was also described in Kashman's paper in 2008 [25]. The soft coral was obtained from Kitagamwa, southern Kenya. The chemical structure of nardosinanol A was tentatively assigned as 2-deoxy-12-oxolemnacarnol.

Table 1. Lemnalia-derived secondary metabolites.

\begin{tabular}{|c|c|c|c|}
\hline Organism & Locality & Secondary Metabolite & Reference \\
\hline \multirow{5}{*}{ Lemnalia africana } & Australia & $\begin{array}{c}(2 R, 7 S, 11 R)-7 \text {-acetoxy-2-hydroxynardosin-1(10)-en-12-al (2), } \\
(2 R, 11 S, 12 R) \text {-lemnal-1(10)-ene-2,12-diol (3), } \\
(2 R, 7 S) \text {-7-formyloxy-2-hydroxy-12-nornardosin-1(10)-en-11-one (5) }\end{array}$ & [9] \\
\hline & $\begin{array}{l}\text { Palau, Western } \\
\text { Caroline Islands }\end{array}$ & $\begin{array}{c}(1 \beta, 2 Z, 4 \beta, 10 \alpha, 12 \beta)-4 \text {-acetoxy-10-hydroxy-neolemna-2,8-dien-5-one } \\
(6),(1 \beta, 2 Z, 4 \beta, 10 \alpha, 12 \beta)-4,10 \text {-diacetoxy-neolemna-2,8-dien-5-one } \\
\text { (7), eremophila-6,10-diene-11,12-diol (8) }\end{array}$ & [14] \\
\hline & Pohnpei, Micronesia & napalilactone (9), compounds 10-11 & [16] \\
\hline & $\begin{array}{l}\text { Pohnpei, } \\
\text { Mincronesia }\end{array}$ & $\begin{array}{l}\text { 4-acetoxy-2,8-neolemnadien-5-one }(\mathbf{1 2}), \\
\text { 12-acetoxy-1(10)-aristolene (13), 2,7-nardosinoxanedione (14), } \\
\text { 4-acetoxy-6,10-guaiadiene }(\mathbf{1 5}), \\
\text { 1(10)-epoxy-2-hydroxy-12-nornardosin-7,11-dione }(\mathbf{1 6}, 6 \beta ; \mathbf{1 7} 6 \alpha), \\
\text { bicyclogermacrene (18), germacrene D }(\mathbf{1 9}), 1,6 \text {-germacradien-5-ol } \\
\text { (20), 1(11),5(12),6-germacratrien-2-ol acetate (21), } \\
\text { 4-acetoxy-10-hydroxy-5-oxo-2,8-neolemnadiene (6), lemnacarnol } \\
\text { (4), 2-oxolemnacarnol (22), 11,12-dihydroxy-6,10-eremophiladiene } \\
\text { (8), 4,10-diacetoxy-5-oxo-2,8-neolemnadiene (7), } \\
\text { 2-acetoxy-1(11),6-germacradien-5-ol (23) }\end{array}$ & [20] \\
\hline & Fundu, Tanzania & nardosinanols G-I (24-26), lemnafricanol (27) & [25] \\
\hline \multirow{4}{*}{ L. flava } & Mombasa, Kenya & lemnaflavoside (28), compounds 29-31 & [26] \\
\hline & Green Island, Taiwan & $\begin{array}{c}(1 S, 2 S, 4 R, 6 S, 7 R, 8 S)-4 \alpha \text {-formyloxy- } \beta \text {-ylangene (32), lemnalol (33), } \\
\text { cervicol (34) }\end{array}$ & [27] \\
\hline & Green Island, Taiwan & flavalins A-D (35-38) & [31] \\
\hline & Green Island, Taiwan & $\begin{array}{c}\text { flavalins E-H (39-42), flavalins I (43) and J (44), } \\
\text { 2-oxolemnacarnol (22), lemnacarnol (4), armatin F (45), } \\
\text { (2R)-2-hydroxylemnal-1(10)-en-12-one (46), and laevinol B (47) }\end{array}$ & [32] \\
\hline \multirow[t]{2}{*}{ L. cervicornis } & $\begin{array}{l}\text { Broadhurst Reef, } \\
\text { Townsville }\end{array}$ & 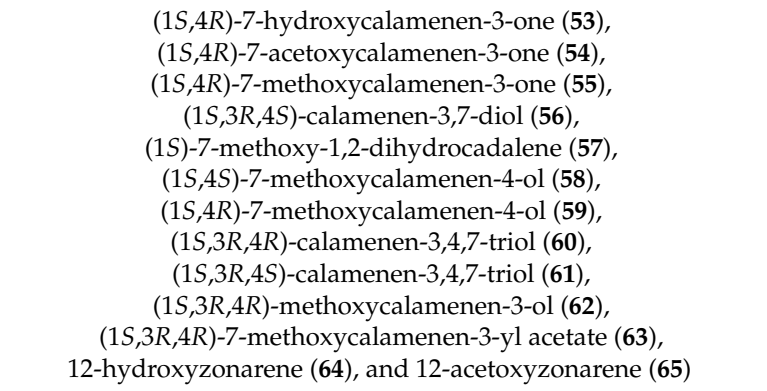 & {$[36]$} \\
\hline & Green Island, Taiwan & $\begin{array}{l}\text { cervicol (34), isolemnalol (66), lemnalol (33), } \\
\text { 4-oxo- } \alpha \text {-ylangene (67) }\end{array}$ & [37] \\
\hline
\end{tabular}


Table 1. Cont.

\begin{tabular}{|c|c|c|c|}
\hline Organism & Locality & Secondary Metabolite & Reference \\
\hline \multirow{2}{*}{ L. bournei } & South China Sea & lemnabourside (68) & [39] \\
\hline & South China Sea & lemnaboursides B (69) and C (70) & [40] \\
\hline L. laevis & $\begin{array}{c}\text { Green Island, off } \\
\text { Taiwan }\end{array}$ & $\begin{array}{l}\text { laevinols A (73), B (47), C-H (74-79), laevinone A (80), } \\
\text { 11,12-dihydroxy-6,10-eremophiladiene (8), and } \\
6 \beta \text {-acetyl-4 } \beta, 5 \beta \text {-dimethyl-1(10) } \alpha \text {-epoxy-2 } \beta \text {-hydroxy-7-oxodecalin }(\mathbf{8 1})\end{array}$ & [33] \\
\hline \multirow{2}{*}{$\begin{array}{l}\text { Unclassified } \\
\text { Lemnalia sp. }\end{array}$} & South China Sea & lemnalosides A-D (84-87), lemnabourside (68) & [43] \\
\hline & Fundu, Tanzania & nardosinanol A (88) & [25] \\
\hline
\end{tabular}

\section{Conclusions and Perspectives}

Extensive efforts have been devoted to implementing chemical investigations of Lemnalia during the past 44 years from 1974 to present. One of the most significant findings to emerge from these studies is the chemical diversity and biological activities of the secondary metabolites from marine soft coral Lemnalia. This paper presents an exhaustive review of these studies including the discovery of small molecules and their biological evaluation.

It is worth noting that the plausible biogenetic pathways of several sesquiterpenoids were proposed. Thus, it could inspire biomimetic syntheses and compound interconversion to scale up the available amounts for further specific pharmacological and toxicological evaluations. Another outlook worth mentioning is the possible biogenetic relationship between some metabolites in this genus. To the best of our knowledge, the production of these diverse metabolites may be due to the unique adaptive strategy of soft corals living in various marine environments [44-46]. For instance, diterpene glycosides were mainly discovered in South China Sea, whereas nornardosinane sesquiterpenoids were mostly isolated from Formosan soft corals. In the future, more chemical investigations of soft corals from specific marine ecological environment are warranted for the demonstration of the chemical ecological significance of these metabolites in the life cycle of Lemnalia. Furthermore, special attention should be paid to symbiotic microorganisms of Lemnalia owing to the fact that some therapeutic agents of marine invertebrates are biosynthesized by their symbiotic microbes. We hold the belief that symbiotic microbes in Lemnalia have taken part in the generation of some metabolites, which could be another direction for the future study. All these efforts would speed up the discovery of functional metabolites, not only from Lemnalia, but also from all precious marine resources.

Author Contributions: Q.W. collected the references and wrote the review; J.S., J.C., and H.Z. offered important advice to improve the review; H.W. and Y.-W.G. conceived the review and greatly revised the paper.

Funding: This project was financially supported by the program of National Natural Science Foundation of China (No. 81773628, No. 81741165, No. 41776139, No. 81520108028, No. 21672230); the National Key Research and Development Program (No. 2017YFE0103100); the National Natural Science Foundation of Zhejiang Province (No. LY16H300008, No. LY16H300007); the Zhejiang Postdoctoral Foundation (Jianwei Chen); the China Postdoctoral Science Foundation (2017M620254).

Acknowledgments: We thank Dr. Hang Ma at University of Rhode Island for kind help for careful proofreading and suggesting changes in this manuscript.

Conflicts of Interest: The authors confirm that this article content has no conflict of interest.

\section{References}

1. Liang, L.F.; Guo, Y.W. Terpenes from the soft corals of the genus Sarcophyton: Chemistry and biological activities. Chem. Biodivers. 2013, 10, 2161-2196. [CrossRef] [PubMed]

2. Hegazy, M.E.F.; Mohamed, T.A.; Alhammady, M.A.; Shaheen, A.M.; Reda, E.H.; Elshamy, A.I.; Aziz, M.; Paré, P.W. Molecular architecture and biomedical leads of terpenes from Red Sea marine invertebrates. Mar. Drugs 2015, 13, 3154-3181. [CrossRef] [PubMed] 
3. Hu, J.; Yang, B.; Lin, X.; Zhou, X.; Yang, X.; Long, L.; Liu, Y. Chemical and biological studies of soft corals of the nephtheidae family. Chem. Biodivers. 2011, 8, 1011-1032. [CrossRef] [PubMed]

4. Ye, F.; Li, J.; Wu, Y.; Zhu, Z.D.; Mollo, E.; Gavagnin, M.; Gu, Y.C.; Zhu, W.L.; Li, X.W.; Guo, Y.W. Sarinfacetamides A and B, nitrogenous diterpenoids with tricyclo[6.3.1.0 1,5]dodecane scaffold from the South China Sea soft coral Sarcophyton infundibuliforme. Org. Lett. 2018, 20, 2637-2640. [CrossRef] [PubMed]

5. Wei, W.C.; Sung, P.J.; Duh, C.Y.; Chen, B.W.; Sheu, J.H.; Yang, N.S. Anti-inflammatory activities of natural products isolated from soft corals of Taiwan between 2008 and 2012. Mar. Drugs 2013, 11, 4083-4126. [CrossRef] [PubMed]

6. Ye, F.; Zhu, Z.D.; Chen, J.S.; Li, J.; Gu, Y.C.; Zhu, W.L.; Li, X.W.; Guo, Y.W. Xishacorenes A-C, diterpenes with bicyclo[3.3.1]nonane nucleus from the Xisha soft coral Sinularia polydactyla. Org. Lett. 2017, 19, 4183-4186. [CrossRef] [PubMed]

7. Tursch, B.; Braekman, J.C.; Daloze, D.; Fritz, P.; Kelecom, A.; Karlsson, R.; Losman, D. Chemical studies of marine invertebrates. VIII. Africanol, an unusual sesquiterpene from Lemnalia africana (Coelenterata, Octocorallia, Alcyonacea). Tetrahedron Lett. 1974, 9, 747-750. [CrossRef]

8. Karlsson, R. Measurements of bijvoet differences. Structure and absolute configuration of africanol, a sesquiterpene. Acta Cryst. 1976, 32, 2609-2614. [CrossRef]

9. Bowden, B.F.; Coll, J.C.; Mitchell, S.J.; Skelton, B.W.; White, A.H. Studies of Australian soft corals. XXII* The structures of two novel sesquiterpenes and a nor sesquiterpene from Lemnalia africana, confirmed by a single-crystal X-Ray study. Aust. J. Chem. 1980, 33, 2737-2747. [CrossRef]

10. Tseng, Y.J.; Lee, Y.S.; Wang, S.K.; Sheu, J.H.; Duh, C.Y. Parathyrsoidins A-D, four new sesquiterpenoids from the soft coral Paralemnalia thyrsoides. Mar. Drugs 2013, 11, 2501-2509. [CrossRef] [PubMed]

11. Lee, Y.S.; Duh, T.H.; Siao, S.S.; Chang, R.C.; Wang, S.K.; Duh, C.Y. New cytotoxic terpenoids from soft corals Nephthea chabroli and Paralemnalia thyrsoides. Mar. Drugs 2017, 15, 392. [CrossRef] [PubMed]

12. Huang, C.Y.; Su, J.H.; Chen, B.W.; Wen, Z.H.; Hsu, C.H.; Dai, C.F.; Sheu, J.H.; Sung, P.J. Nardosinane-type sesquiterpenoids from the Formosan soft coral Paralemnalia thyrsoides. Mar. Drugs 2011, 9, 1543-1553. [CrossRef] [PubMed]

13. Tursch, B.; Colin, M.; Daloze, D.; Losman, D.; Karlsson, R. Chemical studies of marine invertebrates. XII ${ }^{(1)}$. Lemnacarnol, a novel sesquiterpene from the soft coral Lemnalia carnosa (Octocorallia, Alcyonalea). Bull. Soc. Chim. Belg. 1975, 84, 1-2.

14. Izac, R.R.; Fenical, W.; Tagle, B.; Clardy, J. Neolemnane and eremophilane sesquiterpenoids from the pacific soft coral Lemnalia africana. Tetrahedron 1981, 37, 2569-2573. [CrossRef]

15. Bowden, B.F.; Coll, J.C.; Mitchell, S.J. Studies of Australian soft corals. XIX two new sesquiterpenes with the nardosinane skeleton from a Paralemnalia species. Aust. J. Chem. 1980, 33, 885-890. [CrossRef]

16. Carney, J.R.; Pham, A.T.; Yoshida, W.Y.; Scheuer, P.J. Napalilactone, a new halogenated norsesquiterpenoid from the soft coral Lemnalia africana. Tetrahedron Lett. 1992, 33, 7115-7118. [CrossRef]

17. Izac, R.R.; Schneider, P.; Swain, M.; Fenical, W. New nor-sesquiterpenoids of apparent nardosinane origin from the pacific soft-coral Paralemnalia thyrsoides. Tetrahedron Lett. 1982, 23, 817-820. [CrossRef]

18. Bowden, B.F.; Coll, J.C.; Mitchell, S.J.; Nemorin, J.L.E.; Sternhell, S. Studies of Australian soft corals. XXIII the co-occurrence of bicyclogermacrene and lemnacarnol derivatives in Parerythropodium fulvum. Tetrahedron Lett. 1980, 21, 3105-3108. [CrossRef]

19. Vyvyan, J.R.; Rubensa, C.A.; Halfen, J.A. Synthesis of the napalilactone and pathylactone A spirocyclic skeleton. Tetrahedron Lett. 2002, 43, 221-224. [CrossRef]

20. Jurek, J.; Scheuer, P.J. Sesquiterpenoids and norsesquiterpenoids from the soft coral Lemnalia africana. J. Nat. Prod. 1993, 56, 508-513. [CrossRef] [PubMed]

21. Morikawa, K.; Hirose, Y. Germacrene-C, precursor of $\delta$-elemene. Tetrahedron Lett. 1969, 10, $1799-1801$. [CrossRef]

22. Izac, R.R.; Bandurraga, M.M.; Wasylyk, J.M.; Dunn, F.W.; Fenical, W. Germacrene derivatives from diverse marine soft-corals (Octocorallia). Tetrahedron 1982, 38, 301-304. [CrossRef]

23. Fattorusso, E.; Magno, S.; Mayol, L.; Amico, V.; Oriente, G.; Piattelli, M.; Tringali, C. Isolation of $(2 R, 8 R)$-germacra-1(11),5(12),E6-trien-2-ol acetate from the brown alga Dilophus fasciola. Tetrahedron Lett. 1978, 19, 4149-4152. [CrossRef] 
24. Daloze, D.; Braekman, J.C.; Georget, P.; Tursch, B. Chemical studies of marine invertebrates. XXII. Two novel sesquiterpenes from soft corals of the genera Lemnalia and Paralemnalia. Bull. Soc. Chim. Belg. 1977, 86, 47-54. [CrossRef]

25. Bishara, A.; Yeffet, D.; Sisso, M.; Shmul, G.; Schleyer, M.; Benayahu, Y.; Rudi, A.; Kashman, Y. Nardosinanols A-I and lemnafricanol, sesquiterpenes from several soft corals, Lemnalia sp., Paralemnalia clavata, Lemnalia africana, and Rhytisma fulvum fulvum. J. Nat. Prod. 2008, 71, 375-380. [CrossRef] [PubMed]

26. Rudi, A.; Levi, S.; Benayahu, Y.; Kashman, Y. Lemnaflavoside, a new diterpene glycoside from the soft coral Lemnalia flava. J. Nat. Prod. 2002, 65, 1672-1674. [CrossRef] [PubMed]

27. Cheng, S.Y.; Lin, E.H.; Huang, J.S.; Wen, Z.H.; Duh, C.Y. Ylangene-type and nardosinane-type sesquiterpenoids from the Soft corals Lemnalia flava and Paralemnalia thyrsoides. Chem. Pharm. Bull. 2010, 58, 381-385. [CrossRef] [PubMed]

28. Kikuchi, H.; Tsukitani, Y.; Yamada, Y.; Iguchi, K.; Drexler, S.A.; Clardy, J. Lemnalol, a new sesquiterpenoid from the soft coral Lemnalia tenuis verseveldt. Tetrahedron Lett. 1982, 23, 1063-1066. [CrossRef]

29. Duh, C.Y.; El-Gamal, A.A.H.; Song, P.Y.; Wang, S.K.; Dai, C.F. Steroids and sesquiterpenoids from the soft corals Dendronephthya gigantea and Lemnalia cervicorni. J. Nat. Prod. 2004, 67, 1650-1653. [CrossRef] [PubMed]

30. Ohta, Y.; Hirose, Y. Stereochemistry of (+)- $\alpha$-ylangene. Tetrahedron Lett. 1969, 10, 1601-1604. [CrossRef]

31. Lu, Y.; Li, P.J.; Hung, W.Y.; Su, J.H.; Wen, Z.H.; Hsu, C.H.; Dai, C.F.; Chiang, M.Y.; Sheu, J.H. Nardosinane sesquiterpenoids from the Formosan soft coral Lemnalia flava. J. Nat. Prod. 2011, 74, 169-174. [CrossRef] [PubMed]

32. Su, J.H.; Lu, Y.; Hung, W.Y.; Huang, C.Y.; Chiang, M.Y.; Sung, P.J.; Kuo, Y.H.; Sheu, J.H. Sesquiterpenoids from the Formosan soft coral Lemnalia flava. Chem. Pharm. Bull. 2011, 59, 698-702. [CrossRef] [PubMed]

33. El-Gamal, A.A.H.; Chiu, E.P.; Li, C.H.; Cheng, S.Y.; Dai, C.F.; Duh, C.Y. Sesquiterpenoids and norsesquiterpenoids from the Formosan soft coral Lemnalia laevis. J. Nat. Prod. 2005, 68, 1749-1753. [CrossRef] [PubMed]

34. Xio, Y.J.; Su, J.H.; Chen, B.W.; Tseng, Y.J.; Wu, Y.C.; Sheu, J.H. Oxygenated ylangene-derived sesquiterpenoids from the soft coral Lemnalia philippinensis. Mar. Drugs 2013, 11, 3735-3741. [CrossRef] [PubMed]

35. Xio, Y.J.; Su, J.H.; Tseng, Y.J.; Chen, B.W.; Liu, W.; Sheu, J.H. Oxygenated eremophilane- and neolemnane-derived sesquiterpenoids from the soft coral Lemnalia philippinensis. Mar. Drugs 2014, 12, 4495-4503. [CrossRef] [PubMed]

36. Bowden, B.F.; Coll, J.C.; Engelhardt, L.M.; Tapiolas, D.M.; White, A.H. Studies of Australian soft corals. $\mathrm{XXXVI}^{*}$ The isolation and structure determination of 11 calmenene-based sesquiterpenes from Lemnalia cervicornis (Coelenterata, Octocorallia, Alcyonacea). Aust. J. Chem. 1986, 39, 103-121. [CrossRef]

37. Uchio, Y. Isolation and structural determination of vulgarone $a$ and $b$, two novel sesquiterpene ketones from Chrysanthemum vulgare. Tetrahedron 1978, 34, 2893-2899. [CrossRef]

38. Jean, Y.H.; Chen, W.F.; Duh, C.Y.; Huang, S.Y.; Hsu, C.H.; Lin, C.S.; Sung, C.S.; Chen, I.M.; Wen, Z.H. Inducible nitric oxide synthase and cyclooxygenase-2 participate in anti-inflammatory and analgesic effects of the natural marine compound lemnalol from Formosan soft coral Lemnalia cervicorni. Eur. J. Pharmacol. 2008, 578, 323-331. [CrossRef] [PubMed]

39. Zhang, M.; Long, K.; Wu, H.; Ma, K. A novel diterpene glycoside from the soft coral of Lemnalia bournei. J. Nat. Prod. 1994, 57, 155-160. [CrossRef]

40. Zhang, M.; Huang, Z. Two new diterpene glycosides from the soft coral Lemnalia bournei. J. Nat. Prod. 1998, 61, 1300-1301. [CrossRef] [PubMed]

41. Kikuchi, H.; Manda, T.; Kobayashi, K.; Yamada, Y.; Iguchi, K. Anti-tumor activity of lemnalol isolated from the soft coral Lemnalia tenuis verseveldt. Chem. Pharm. Bull. 1983, 31, 1086-1088. [CrossRef] [PubMed]

42. Bowden, B.F.; Coll, J.C.; Mitchell, S.J. Studies of Australian soft corals. XVI* two new sesquiterpenes from Lemnalia humesi. Aust. J. Chem. 1980, 33, 681-684. [CrossRef]

43. Yao, G.; Vidor, N.B.; Foss, A.P.; Chang, L.C. Lemnalosides A-D, decalin-type bicyclic diterpene glycosides from the marine soft coral Lemnalia sp. J. Nat. Prod. 2007, 70, 901-905. [CrossRef] [PubMed]

44. Li, Y.; Pattenden, G. Novel macrocyclic and polycyclic norcembranoid diterpenes from Sinularia species of soft coral: Structural relationships and biosynthetic speculations. Nat. Prod. Rep. 2011, 28, 429-440. [CrossRef] [PubMed] 
45. Chen, W.T.; Li, J.; Wang, J.R.; Li, X.W.; Guo, Y.W. Structural diversity of terpenoids in the soft coral Sinularia flexibilis, evidenced by a collection from the South China Sea. RSC Adv. 2015, 5, 23973-23980. [CrossRef]

46. Coll, J.C. The chemistry and chemical ecology of octocorals (Coelenterata, Octocorallia). Chem. Rev. 1992, 92, 613-631. [CrossRef] 